\title{
Measurement of Diaphragmatic Blood Flow and Oxygen Consumption in the Dog
} by the Kety-Schmidt Technique

\author{
DUdLEY F. ROCHESTER \\ From the Cardio-Respiratory Laboratory, Department of Medicine, Columbia \\ University, College of Physicians \& Surgeons, New York 10032
}

A B S T R A C T To assess energy expenditure of the diaphragm directly, a method was devised for percutaneous catheterization of the left inferior phrenic vein in dogs. Necropsy studies, including retrograde injection of india ink and measurement of radioactivity in diaphragmatic muscle strips, suggested that the territory drained by the inferior phrenic vein was uniformly perfused, and that there were no major anastomoses between this bed and adjacent ones.

Diaphragmatic blood flow ( $\dot{Q}$ di) was calculated from the integrated diaphragmatic arteriovenous difference of ${ }^{86} \mathrm{Kr}$ by the Kety-Schmidt technique. Diaphragmatic oxygen consumption ( $\dot{\mathrm{V}}_{\mathrm{O} 2} \mathrm{di}$ ) was determined as the product of $\dot{Q}$ di and the diaphragmatic arteriovenous oxygen content difference $\left[(\mathrm{A}-\mathrm{V}) \mathrm{O}_{2}\right.$ di]. When lightly anesthetized dogs breathed quietly, $\dot{Q}$ di was $22 \pm \mathrm{SD} 6$ $\mathrm{ml} / \mathrm{min} / 100 \mathrm{~g}$, (A-V) $\mathrm{O}_{2}$ di was $6.1 \pm \mathrm{SD} 2.5 \mathrm{ml} / 100 \mathrm{ml}$, and $\dot{\mathrm{V} O} 2$ di averaged $1.2 \pm \mathrm{SD} 0.3 \mathrm{ml} / \mathrm{min} / 100 \mathrm{~g}$. This represented $1.0 \pm \mathrm{SD} 0.2 \%$ of total body oxygen consumption. $\dot{\mathrm{V}}_{2}$ di remained relatively constant during quiet breathing, whereas $\dot{Q}$ di varied directly with cardiac output and reciprocally with $(\mathrm{A}-\mathrm{V}) \mathrm{O}_{2} \mathrm{di}$. The oxygen consumption of the noncontracting diaphragm was $60 \pm \mathrm{SD} 20 \%$ - of the level measured during quiet breathing.

The energy expended by the diaphragm to support simple hyperventilation was small. A $100 \%$ increase in minute ventilation, induced by inhalation of $5 \% \mathrm{CO}_{2}$ in $21 \%$ or $14 \% \mathrm{O}_{2}$, increased $\dot{Q}$ di $13 \%,(\mathrm{~A}-\mathrm{V}) \mathrm{O}_{2}$ di $19 \%$, and $\dot{\mathrm{VO}}_{2}$ di $40 \%$. The diaphragm consumed $0.13 \pm$

This work was presented in part at the 62nd Annual Meeting of the American Society for Clinical Investigation, Inc., Atlantic City, N. J., May 1970, and published in abstract form (J. Clin. Invest. 1970. 49: 80a.).

Received for publication 4 June 1973 and in revised form 4 January 1974.
$\mathrm{SD} 0.09 \mathrm{ml} \mathrm{O}$ 年 for each additional liter of ventilation. In four dogs, pneumonia appeared to increase $\dot{\mathrm{V}} \mathrm{O}_{2}$ both by increasing minute ventilation and by increasing the energy cost per liter of ventilation.

\section{INTRODUCTION}

Diseases characterized by an increased work of breathing impose an excessive burden on the respiratory muscles. Evaluation of the ability of the respiratory musculature to sustain acute and chronic increases in work load would be enhanced greatly by knowledge of the blood flow to and oxygen consumption of individual inspiratory muscles.

Blood flow to the diaphragm and intercostal muscles has been assessed to only a limited degree. While the direction of change consequent to certain physiologic interventions has been established, accurate quantification of the level of perfusion has not been achieved $(1-4)$. The oxygen consumption of all the respiratory muscles has been repeatedly evaluated by the indirect method of Liljestrand (5-13), but with the exception of preliminary results from this laboratory (14), no data concerning direct measurement of the oxygen consumption of an individual respiratory muscle have been reported.

During an earlier study of diaphragmatic blood flow we reexamined the arrangement of the veins draining the canine diaphragm, and found that tributaries on the abdominal surface of each hemidiaphragm join to form common trunks, which enter the inferior vena cava cephalad to the hepatic veins. The trunk on the left is $3-4 \mathrm{~cm}$ long and about $0.5 \mathrm{~cm}$ in diameter at the caval orifice, which led us to believe it could be catheterized by conventional percutaneous techniques.

The purposes of this report are, first, to outline the techniques used to catheterize the left inferior phrenic 
vein and describe the methods used to measure diaphragmatic blood flow, arteriovenous oxygen difference, and oxygen consumption. Secondly, the determinants of diaphragmatic blood flow and oxygen consumption will be assessed at three levels of diaphragmatic energy expenditure: when it is not contracting, when it is supporting quiet breathing, and during hyperventilation. Finally, the report will evaluate the diaphragmatic oxygen cost of breathing, both in relation to total body oxygen consumption and in terms of the energy required to increase the minute ventilation.

\section{METHODS}

\section{Animal preparation}

All studies were performed in adult mongrel dogs weighing $17-37 \mathrm{~kg}$. The animals were initially anesthetized with $25 \mathrm{mg} / \mathrm{kg}$ of pentobarbital. Upon completion of surgical procedures, the level of anesthesia was adjusted with an intravenous drip of $5 \%$ thiamylal sodium so that the inner corneal reflex was retained.

The trachea was intubated with a cuffed tube passed through the larynx. A double-lumen catheter was advanced via the right femoral vein so that the distal lumen lay in the right atrium and the proximal lumen was in the inferior vena cava. The proximal lumen was used for maintenance anesthesia, while the distal lumen was reserved for krypton infusion or dye injection. A femoral artery was cannulated.

\section{Measurement of diaphragmatic blood flow}

Catheterization technique. To catheterize the left inferior phrenic vein, a 7 french Hannafee Nash catheter, 80 $\mathrm{cm}$ long, was fitted with a guide wire that had an adjustable curve at the tip (Rotoflector, United States Catheter \& Instrument Corp., Glen Falls, N. Y.). The catheter had been previously modified by cutting two additional side holes within $1 \mathrm{~cm}$ of the tip in order to prevent the catheter from occluding the diaphragmatic venous outflow. This assembly was introduced without a curve into the left femoral vein and advanced under fluoroscopic control into the thoracic portion of the inferior vena cava. The tip was then curved to a right angle, and the catheter was rotated so that the tip pointed directly to the left side of the animal. The catheter assembly was then withdrawn to a site just below the shadow of the dome of the diaphragm and the catheter was advanced over the curved guide wire. When the left inferior phrenic vein was entered successfully, the catheter could be advanced horizontally across the midline below the heart shadow until the tip nearly intersected the left hemidiaphragm silhouette. To facilitate visualization of the catheter, $50 \%$ aqueous Hypaque solution (Winthrop Laboratories, Div. of Sterling Drug, Inc., New York) was injected. The appearance of the catheter in the phrenic vein and other details of the preparation are depicted in Fig. 1. When the catheter entered a hepatic vein instead of the left inferior phrenic vein, the catheter always appeared well below the dome of the diaphragm, and usually pointed in a somewhat caudad direction. Correct catheter position was confirmed at necropsy in all animals.

The left inferior phrenic vein was cannulated successfully in $80 \%$ of the animals, but most attempts to catheterize the right inferior phrenic vein failed. Although the latter

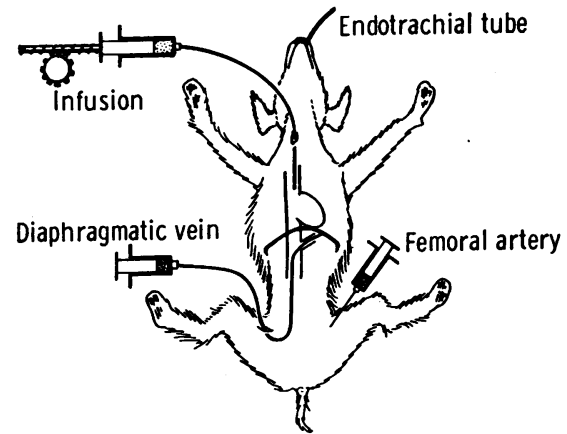

FIGURE 1 Diagram of experimental preparation. The infusion is shown entering the right atrium. After the first set of studies, the infusion catheter was passed retrograde from a femoral artery to the left ventricle. See text.

vein could be entered, the trunk was so short that the catheter usually snapped out spontaneously.

The anatomy of the inferior phrenic venous bed was further explored by retrograde injection of india ink at necropsy. The muscle sheet between the central tendon and the chest wall was intensely and uniformly stained. There was almost no staining beyond the attachment of the diaphragm to the chest wall. These findings suggest that the inferior phrenic venous bed in the dog drains primarily diaphragmatic muscle tissue, without significant anastomoses to venous beds draining other organs.

Administration and measurement of radioactivity. Blood flow per $100 \mathrm{~g}$ of diaphragm was measured by the KetySchmidt method $(15,16)$, as modified by Hansen et al. (17). For each determination, krypton-85 dissolved in saline was infused intravenously at a rate of $250 \mu \mathrm{Ci} / \mathrm{min}$ for 20 min. In all but the first 15 studies, counting rates were increased and the radiation dose was decreased by infusing via a retrograde arterial catheter into the left ventricle. During and shortly after the infusion, all expired air was collected in a large spirometer and transferred to balloons to avoid radioactive contamination of the room air.

Arterial blood krypton concentration rises rapidly after the start of the infusion, and achieves stable values within ninutes, whereas the inferior phrenic venous blood tracer level rises more slowly toward the equilibrium concentration. Upon abrupt cessation of the infusion, the arterial blood krypton concentration falls rapidly to near zero, while the inferior phrenic venous concentration falls at a slower rate. This is the washout phase (Fig. 2).

To establish the krypton concentration-time curves with accuracy, it is necessary to sample blood from the femoral artery and inferior phrenic vein at 1-2-min intervals for 15 min. The volume of the phrenic vein catheter is about 1 $\mathrm{ml}$; it is flushed by withdrawing and discarding $3 \mathrm{ml}$ of blood before collecting the $4 \mathrm{ml}$ of blood needed for each analysis. Blood is sampled at $5-6 \mathrm{ml} / \mathrm{min}$. This rate is similar to that used by Kety and Schmidt (16). The blood krypton concentration was determined by the method of Hardewig, Rochester, and Briscoe (18).

To determine whether or not blood sampled from the left inferior phrenic vein was contaminated by retrograde flow of blood from the inferior vena cava, a separate protocol was carried out for eight runs in three dogs. Saline containing ${ }^{138} \mathrm{Xe}$ was infused at a constant rate into the inferior vena cava just cephalad to the femoral veins. Blood 


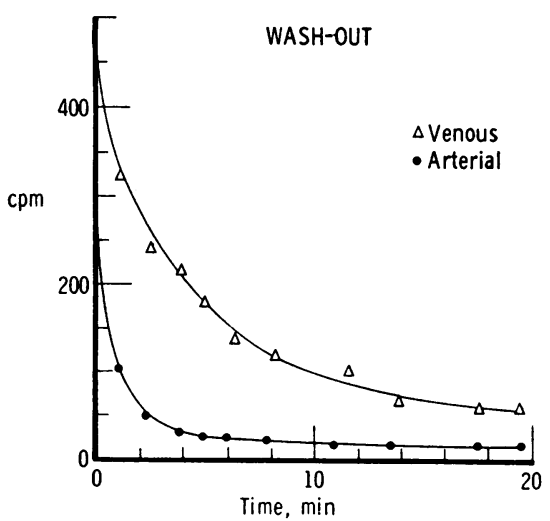

Figure 2 Arterial blood krypton concentrations, denoted by closed circles $(\bullet)$, and diaphragmatic venous blood krypton concentrations, denoted by open triangles $(\Delta)$, during the washout phase, after the infusion had stopped.

was collected simultaneously from the left inferior phrenic vein, the thoracic portion of the inferior vena cava, and a femoral artery. Four sets of samples were collected at approximately $15,35,55$, and $75 \mathrm{~s}$ after the infusion began. Each sample consisted of exactly $2 \mathrm{ml}$ of blood collected in a disposable $10-\mathrm{ml}$ plastic syringe. The sampling rate was varied from 5 to $10 \mathrm{ml} / \mathrm{min}$. The blood xenon concentration was measured by counting each syringe in a well counter (Picker Nuclear Intertech, North Haven, Conn.).

Uniformity of blood flow to the left hemidiaphragm was assessed by measuring radioactivity in excised strips of diaphragm in three animals. Saline containing dissolved ${ }^{133} \mathrm{Xe}$ was infused at a constant rate into the left ventricle of three dogs. After $20 \mathrm{~min}$ the infusion was stopped and blood samples were collected at half-min intervals from the femoral artery and left inferior phrenic vein. After $3 \mathrm{~min}$, at which time the xenon level in inferior phrenic venous blood had fallen to about half the level present just before the infusion stopped, the dogs were killed by an overdose of pentobarbital. The abdomen was opened, the left hemidiaphragm was excised, and strips weighing about $1.5 \mathrm{~g}$ were cut from representative areas. These pieces were put in screw-top counting vials, which were promptly sealed and counted in a well counter. After counting the wet weight of each piece was measured. To correct for the rate at which xenon diffused from the excised strips, some pieces were recounted after successive 10-min interval exposures to air. All results were expressed as counts per milligram wet weight of tissue.

Calculations. To apply the Kety-Schmidt analysis, it is necessary to determine both the equilibrium tracer concentration at the end of the infusion and the integrated arteriovenous difference in indicator concentration, which is graphically represented by the area between the arterial and phrenic venous concentration-time curves (Fig. 2). The measured arterial and diaphragmatic venous blood krypton concentrations were plotted against time and fitted by eye with the best curves. Arterial krypton concentrations during the washin phase were frequently erratic, and since in preliminary studies there was no significant difference between blood flow and oxygen consumption values measured from the washin as compared to the washout phase, only data obtained during the latter period were analyzed.
The diaphragmatic venous blood krypton level frequently failed to reach the arterial level within $20-40 \mathrm{~min}$ of infusion. When this happened, the venous level was taken as the equilibrium value, because after cessation of a prolonged infusion of either xenon or hydrogen, muscle tissue and muscle venous blood tracer levels decay at virtually the same rate $(19,20)$.

To obtain the integrated arteriovenous difference, the smoothed arterial and diaphragmatic venous concentrationtime curves were read every half-min, and the difference between the curves was computed. The area between the curves, expressed as the product of the concentration difference and time in minutes, was computed as the sum of the differences for each half minute divided by two.

The venous tracer level at the end of the sampling period was usually higher than the arterial tracer level, with the result that there was a persistent arteriovenous tracer concentration difference. To complete the area between the curves, it was necessary to adopt an extrapolation procedure. The difference between recorded arterial and diaphragmatic venous tracer curves was plotted as a function of time on semilogarithmic paper. The tail end of the resultant arteriovenous difference curve was fitted with a straight line. The area between the unrecorded parts of the arterial and venous concentration-time curve was then computed as the product of the last measured arteriovenous concentration difference and the time constant of the tail of the arteriovenous concentration difference curve.

The ratio of equilibrium tracer concentration to the integrated arteriovenous tracer concentration difference equals the ratio of blood flow to the effective volume of tracer distribution in the Kety-Schmidt method $(15,16)$. To convert effective volume to muscle mass, it is necessary to correct for the relative densities of blood and muscle and for the blood-muscle partition coefficient of the tracer. Since both correction factors have values near unity (2123), no numerical corrections was made. Thus, the formula used to calculate diaphragmatic blood flow ( $\dot{Q}$ di) was $\dot{Q} \mathrm{di}=100 \times$ (equilibrium concentration/area), in milliliters per minute per 100 grams.

The oxygen consumption of the diaphragm was calculated as the product of diaphragmatic blood flow and arteriovenous difference in oxygen content, using the formula:

$$
\dot{\mathrm{V}}_{2} \mathrm{di}=\left[\dot{\mathrm{Q}} \mathrm{di} \times(\mathrm{A}-\mathrm{V}) \mathrm{O}_{2} \mathrm{di}\right] / 100
$$

where $\dot{\mathrm{V}} \mathrm{O}_{2}$ di and $\dot{\mathrm{Q}}$ di are, respectively, diaphragmatic oxygen consumption and blood flow expressed as milliliters per minute per 100 grams, and $(\mathrm{A}-\mathrm{V}) \mathrm{O}_{2}$ di is diaphragmatic arteriovenous oxygen content difference in $\mathrm{ml} / 100 \mathrm{ml}$. Blood oxygen content was measured by the method of Van Slyke and Neill (24)

Diaphragmatic blood flow and oxygen consumption were converted to absolute values by multiplying the value per $100 \mathrm{~g}$ by the weight of the diaphragm. Weight was estimated from the highly significant relationship previously established in the dog (4): diaphragmatic wt in grams = $25.09+4.15$ body wt in kilograms.

\section{Minute ventilation, cardiac output, and blood pressure}

Minute ventilation was measured by attaching the endotracheal tube to a low-resistance, low dead space directional breathing valve connected to a 120 -liter Tissot spirometer. Minute ventilation was expressed either as liters

\section{$1218 \quad$ D. F. Rochester}


body temperature and pressure, saturated with water vapor (BTPS) per minute per kilogram or as liters BTPS per minute. Cardiac output was determined from the femoral arterial blood concentration-time curves inscribed after bolus injection of indocyanine green dye (25).

\section{Experimental protocol}

Diaphragmatic blood flow and oxygen consumption were determined in three experimental conditions: while the animals breathed quietly; during hyperventilation induced by administration of $5 \% \mathrm{CO}_{2}$ in $14 \%$ or $21 \%$ oxygen; and when the diaphragm was not contracting. During the noncontracting periods, the animals were ventilated with a volume respirator (Model 614 Respiration Pump, Harvard Apparatus Co., Inc., Millis, Mass.). Diaphragmatic contraction was abolished either by hyperventilation to the point where diaphragmatic electrical activity disappeared, or by administration of a loading dose of $20 \mathrm{mg}$ of succinyl choline followed by a maintenance infusion of 1-2 $\mathrm{mg} / \mathrm{min}$.

Blood removed for measurement of krypton and dye concentrations was replaced by an equivalent volume of normal saline to prevent hypovolemia.

\section{RESULTS}

Analysis of the xenon levels in blood obtained from the left inferior phrenic vein, the thoracic portion of the inferior vena cava, and from a systemic artery during infusion of xenon into the lower inferior vena cava revealed a consistent picture (Fig. 3 ). The xenon level in thoracic inferior vena cava blood rose rapidly to a plateau within two min. Radioactivity in systemic arterial blood rose slowly to $12-20 \%$ of the thoracic inferior vena cava level. Radioactivity in phrenic venous blood remained at background levels for $\frac{1}{2}$ min., then rose very slowly to about $\frac{1}{4}$ the systemic arterial level. These results were unaffected by varying the sampling rate in the inferior phrenic vein from 5 to $10 \mathrm{ml} / \mathrm{min}$.

These observations indicate that there is no contamination of inferior phrenic venous blood with inferior vena cava blood. The only way the tracer reaches inferior phrenic venous blood is through perfusion of diaphragm muscle by xenon-labeled systemic arterial blood.

Diaphragm muscle tissue levels of ${ }^{139} \mathrm{Xe}$ were measured at necropsy in three dogs. In each animal the crural muscle fibers had high levels of radioactivity per milligram wet weight, whereas the thin sheets of muscle halfway between central tendon and chest wall contained about half as much radioactivity per unit weight. Muscle obtained at the junction with the central tendon or the chest wall had intermediate levels of activity. The central tendon itself contained almost no ${ }^{188} \mathrm{Xe}$. When muscle strips were exposed to air, the tissue radioactivity fell to half its original value in about $20 \mathrm{~min}$. This rate is too slow to explain the differences in levels of radioactivity between the flat muscle sheet and crural portion of the diaphragm.

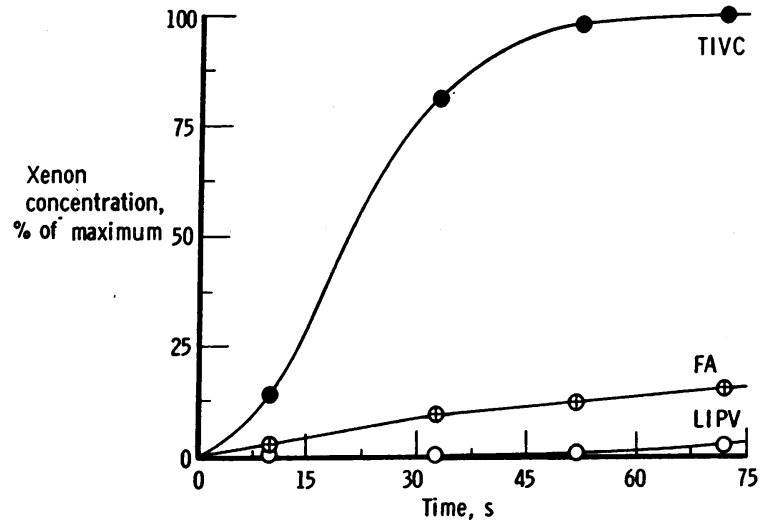

FIGURE 3 The concentrations of ${ }^{139} \mathrm{Xe}$ in thoracic inferior cava blood (TIVC), in femoral arterial blood (FA), and left inferior phrenic venous blood (LIPV) during the first 2 min of constant rate infusion of ${ }^{133} \mathrm{Xe}$ in saline into the lower inferior vena cava.

The reproducibility of the methods was evaluated from two consecutive determinations of diaphragmatic blood flow and oxygen consumption made under the same physiologic conditions of either quiet breathing or hyperventilation. The reproducibility coefficient was calculated as the difference between two consecutive determinations expressed as a percent of the mean of the two determinations. The sign of the difference was ignored. For blood flow, the reproducibility coefficient average $20 \pm \mathrm{SD} 11 \%$; for oxygen consumption it averaged $11 \pm$ SD $6 \%$.

Values of minute ventilation and of diaphragmatic blood flow, arteriovenous oxygen difference, and oxygen consumption measured in 23 healthy dogs during quiet breathing are summarized in Table I. In the healthy animals minute ventilation averaged $0.204 \pm$ SD 0.069 liter/min per $\mathrm{kg}$; diaphragmatic blood flow was $22 \pm \mathrm{SD}$ $6 \mathrm{ml} / \mathrm{min}$ per $100 \mathrm{~g}$; the diaphragmatic arteriovenous oxygen content difference was $6.1 \pm \mathrm{SD} 2.5 \mathrm{ml} / 100 \mathrm{ml}$ and diaphragmatic oxygen consumption was $1.2 \pm \mathrm{SD} 0.3 \mathrm{ml} /$ min per $100 \mathrm{~g}$. During the control period, diaphragmatic blood flow was significantly dependent on cardiac output (Fig. 4), and the average ratio of diaphragmatic blood flow to cardiac output was $0.9 \pm$ SD $0.3 \%$. Neither diaphragmatic blood flow nor oxygen consumption was significantly related to minute ventilation during quiet breathing (Fig. 5).

In the animals with pneumonia, minute ventilation, diaphragmatic blood flow, oxygen extraction, and oxygen consumption were all significantly greater than in healthy dogs. The increases were roughly proportional to the gross anatomic extent of lung involvement. Dog 21 had scattered small grey infiltrates throughout both lungs with healthy-looking areas inbetween. Dog 55 had congestion and consolidation limited to the posterior 


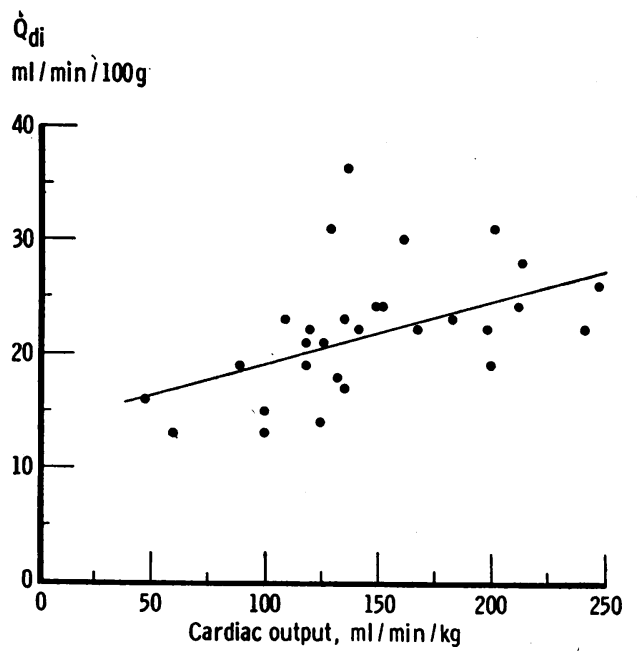

FIgURE 4 Diaphragmatic blood flow ( $\dot{Q}$ di) as a function of cardiac output in healthy dogs at rest. The equation of the regression line is $y=13.60+0.057 x \quad(n=29, r=$ $0.499, t=2.98, P<0.01$ ).

portions of the right lung. Dog 46 had extensive bilateral congestion, edema, and consolidation. Dog 48 aspirated vomitus before intubation, and at necropsy had pneumonia involving virtually all of each lung. In contrast to healthy animals, there was a suggestive correlation between diaphragmatic blood flow and minute ventilation $(n=4, r=0.88, t=2.62, P<0.1)$ and the correlation between diaphragmatic oxygen consumption and minute ventilation was significant $(n=4, r=0.98$, $t=7.40, P<0.02$ ).

During quiet breathing, diaphragmatic blood flow and the diaphragmatic arteriovenous oxygen extraction

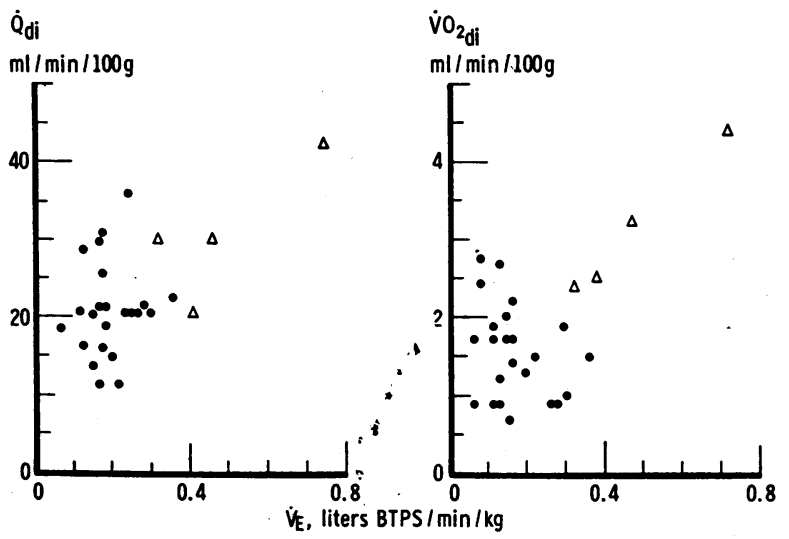

Figure 5 Diaphragmatic blood flow ( $\dot{Q}$ di) and oxygen consumption $\left(\dot{\mathrm{V}}_{2}\right.$ di) as functions of minute ventilation $\left(\dot{V}_{\mathbf{B}}\right)$ during quiet breathing. Data for normal animals are denoted by the closed circles $(\bullet)$, and for dogs with pneumonia by the open triangles $(\Delta)$. had a reciprocal relationship in healthy dogs (Table $I$, Fig. 6). The regression equation describing the relationship between the reciprocal of the arteriovenous oxygen content difference and blood flow to the diaphragm was $[1 /(\mathrm{A}-\mathrm{V}) \mathrm{O}, \mathrm{di}]=0.00877 \dot{\mathrm{Q}} \mathrm{di}-0.0015(n=23, r=$ $0.708, t=4.59, P<0.001)$. Since the intercept value is not significantly different from zero $(P<0.001)$ it was ignored, and the regression line was replotted as the rectangular hyperbola in Fig. 6, which relates the

\section{TABLE I}

Diaphragmatic Blood Flow $(\dot{Q}$ di), Arteriovenous Oxygen Difference $\left[(A-V) O_{2}\right.$ di], Oxygen Consumption

$\left(\dot{V}_{2} d i\right)$, and Minute Ventilation $\left(\dot{V}_{E}\right)$ in 23 Normal and 4 Sick Dogs during Quiet Breathing, at Rest

\begin{tabular}{|c|c|c|c|c|}
\hline Dog & $\grave{Q} \mathbf{d i}$ & $(\mathrm{A}-\mathrm{V}) \mathrm{O}_{2} \mathrm{di}$ & $\dot{\mathrm{V}} \mathrm{o}_{2} \mathrm{di}$ & $\dot{\mathbf{V}} \mathbf{E}$ \\
\hline & $\mathrm{ml} / \mathrm{min} / 100 \mathrm{~g}$ & vol \% & $\mathrm{ml} / \mathrm{min} / 100 \mathrm{~g}$ & $\begin{array}{c}\text { liter BTPS/ } \\
\mathrm{min} / \mathrm{kg}\end{array}$ \\
\hline
\end{tabular}

Healthy dogs

$\begin{array}{lrrrr}10 & 14 & 5.2 & 0.7 & 0.147 \\ 11 & 24 & 6.5 & 1.5 & 0.366 \\ 12 & 16 & 10.8 & 1.7 & 0.173 \\ 13 & 13 & 11.7 & 1.5 & 0.218 \\ 15 & 15 & 8.8 & 1.3 & 0.202 \\ 20 & 13 & 10.2 & 1.4 & 0.166 \\ 22 & 17 & 5.3 & 0.9 & 0.132 \\ 24 & 21 & 4.3 & 0.9 & 0.122 \\ 25 & 19 & 5.0 & 0.9 & 0.065 \\ 26 & 21 & 7.9 & 1.7 & 0.152 \\ 27 & 23 & 7.8 & 1.8 & 0.299 \\ 35 & 22 & 4.5 & 1.0 & 0.305 \\ 36 & 22 & 4.1 & 0.9 & 0.270 \\ 39 & 30 & 4.2 & 1.2 & 0.175 \\ 40 & 23 & 5.5 & 1.3 & 0.268 \\ 41 & 19 & 6.7 & 1.2 & 0.185 \\ 42 & 22 & 4.2 & 0.9 & 0.275 \\ 44 & 28 & 4.5 & 1.3 & 0.139 \\ 45 & 36 & 2.6 & 0.9 & 0.247 \\ 50 & 31 & 4.3 & 1.4 & 0.201 \\ 51 & 22 & 7.7 & 1.7 & 0.228 \\ 52 & 26 & 5.6 & 1.4 & 0.189 \\ 53 & 23 & 3.2 & 0.7 & 0.178 \\ \text { Mean } & 22 & 6.1 & 1.2 & 0.204 \\ \text { SD } & 6 & 2.5 & 0.3 & 0.069\end{array}$

Dogs with pneumonia

$\begin{array}{lcccc}21 & 21 & 11.8 & 2.5 & 0.391 \\ 46 & 30 & 10.7 & 3.2 & 0.447 \\ 48 & 45 & 9.6 & 4.4 & 0.716 \\ 55 & 29 & 8.3 & 2.4 & 0.323 \\ \text { Mean } & 31 & 10.1 & 3.1 & 0.469 \\ \text { SD } & 10 & 1.5 & 0.9 & 0.172 \\ t & 2.70 & 3.11 & 7.80 & 5.64 \\ P & <0.02 & <0.01 & <0.001 & <0.001\end{array}$


TABLE II

Diaphragmatic Blood Flow ( $\dot{Q}$ di), Arteriovenous Oxygen Difference $\left[(\mathrm{A}-\mathrm{V}) \mathrm{O}_{2}\right.$ di], and Oxygen Consumption

$\left(\dot{V}_{2}\right.$ di) during Quiet Breathing $(Q B)$ and when the Diaphragm is not Contracting $(N C)$

\begin{tabular}{|c|c|c|c|c|c|c|c|}
\hline \multirow[b]{2}{*}{ Dog } & \multicolumn{2}{|c|}{$\dot{Q} \mathrm{di}$} & \multicolumn{2}{|c|}{$(A-V) O_{2} d i$} & \multicolumn{2}{|c|}{$\dot{\mathrm{V}}_{2} \mathrm{di}$} & \multirow{2}{*}{$\frac{\dot{\mathrm{V}} \mathrm{O}_{2} \mathrm{di} \mathrm{NC}}{\mathrm{VO}_{2} \mathrm{di} Q B}$} \\
\hline & QB & NC & QB & NC & QB & NC & \\
\hline & \multicolumn{2}{|c|}{$\mathrm{ml} / \mathrm{min} / 100 \mathrm{~g}$} & \multicolumn{2}{|c|}{ Vol \% } & \multicolumn{2}{|c|}{$\mathrm{ml} / \mathrm{min} / 100 \mathrm{~g}$} & \\
\hline \multicolumn{8}{|c|}{ Healthy dogs } \\
\hline 35 & 22 & 16 & 4.5 & 4.9 & 1.0 & 0.8 & 0.8 \\
\hline 36 & 22 & 22 & 4.1 & 3.3 & 0.9 & 0.7 & 0.8 \\
\hline 52 & 26 & 18 & 5.6 & 2.1 & 1.4 & 0.4 & 0.3 \\
\hline 56 & 18 & 11 & 4.2 & 3.4 & 0.8 & 0.4 & 0.5 \\
\hline 58 & 18 & 21 & 7.0 & 3.0 & 1.2 & 0.6 & 0.5 \\
\hline Mean & 21 & 18 & 5.1 & 3.3 & 1.1 & 0.6 & 0.6 \\
\hline SD & 3 & 4 & 1.2 & 1.0 & 0.2 & 0.2 & 0.2 \\
\hline$t$ & \multicolumn{2}{|c|}{1.46} & \multicolumn{2}{|c|}{2.45} & \multicolumn{2}{|c|}{3.58} & \\
\hline$P$ & \multicolumn{2}{|c|}{$<0.2$} & \multicolumn{2}{|c|}{$<0.05$} & \multicolumn{2}{|c|}{$<0.01$} & \\
\hline
\end{tabular}

diaphragmatic arteriovenous oxygen content difference to diaphragmatic perfusion. The equation of this line is: $(\mathrm{A}-\mathrm{V}) \mathrm{O}_{2} \mathrm{di} \times \dot{\mathrm{Q}} \mathrm{di}=114$, which corresponds to a diaphragmatic oxygen consumption of $1.14 \mathrm{ml} / \mathrm{min}$ per $100 \mathrm{~g}$.

Total body oxygen consumption was measured in five dogs. The absolute value of diaphragmatic oxygen consumption, obtained as the product of the oxygen consumption per $100 \mathrm{~g}$ and diaphragmatic weight, averaged $1.0 \pm \mathrm{SD} 0.2 \%$ of total body oxygen consumption during quiet breathing.

Diaphragmatic contraction was abolished by succinyl choline in two dogs and by hyperventilation with a volume respirator in three animals. The oxygen consumption of the resting diaphragm was $60 \pm$ SD $20 \%$ of the value measured during quiet breathing (Table II). The difference between the levels of diaphragmatic oxygen consumption measured during quiet breathing and when the diaphragm was at rest was significant $(t=3.50, P<0.01)$.

The effects on 16 dogs of breathing $5 \% \mathrm{CO}_{2}$ in either $21 \%$ or $14 \%$ oxygen are shown in Fig. 7. Minute ventilation rose significantly $(P<0.001)$ from an average of $0.238 \pm \mathrm{SD} 0.070 \mathrm{liter} / \mathrm{min}$ per $\mathrm{kg}$ to an average of $0.833 \pm \mathrm{SD} 0.361 \mathrm{liter} / \mathrm{min}$ per $\mathrm{kg}$. Diaphragmatic blood flow increased in 14 of the 16 animals. The one dog that had a fall in blood flow during hyperventilation had an unusually high level of diaphragmatic perfusion during the control period. Blood flow averaged $20 \pm S D 5 \mathrm{ml} / \mathrm{min}$ per $100 \mathrm{~g}$ of diaphragm during quiet breathing, and $25 \pm \operatorname{SD~} 5 \mathrm{ml} / 100 \mathrm{~g}$ during $\mathrm{CO}_{2}$-induced hyperventilation. The increase, though slight, was significant $(P<0.01)$. The greater diaphragmatic arteriovenous oxygen content difference was also significant $(P<0.01)$.

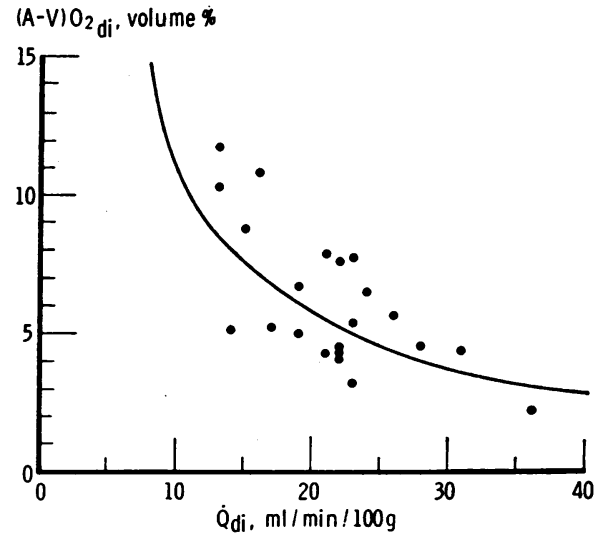

FIGURE 6 Diaphragmatic arteriovenous oxygen content difference $\left[(\mathrm{A}-\mathrm{V}) \mathrm{O}_{2}\right.$ di] as a function of diaphragmatic blood flow ( $\dot{Q}$ di) in healthy dogs at rest. The equation of the rectangular hyperbola is: $(\mathrm{A}-\mathrm{V}) \mathrm{O}_{2} \mathrm{di} \times \dot{\mathrm{Q}} \mathrm{di}=114$. See text for details.

Hyperventilation consistently elevated diaphragmatic oxygen consumption, but to a variable extent (Fig. 7). During quiet breathing these diaphragms utilized $1.2 \pm$ $\mathrm{SD} 0.3 \mathrm{ml}$ of $\mathrm{O}_{2} / \mathrm{min}$ per $100 \mathrm{~g}$. Utilization rose signifi-
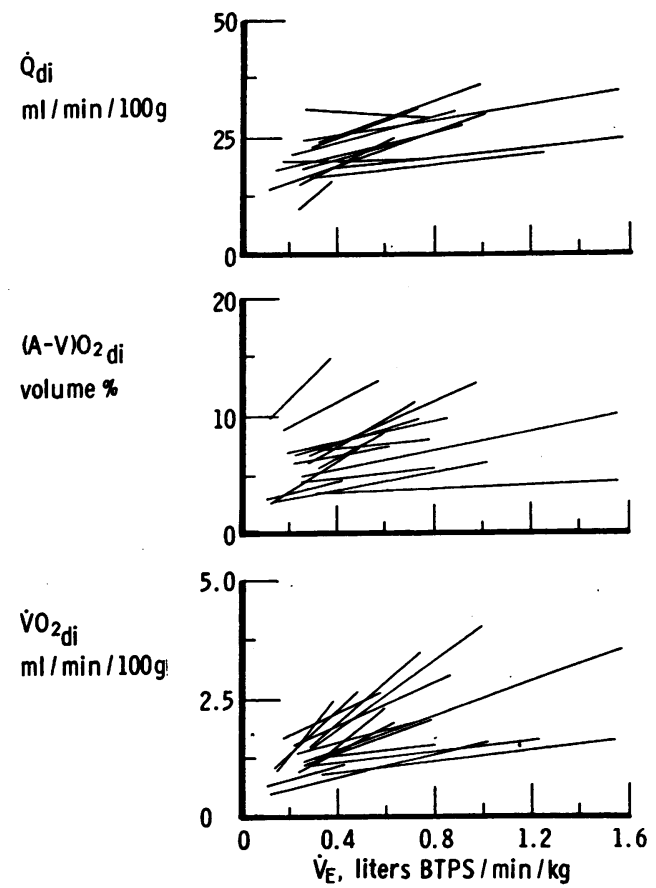

Figure 7 Diaphragmatic blood flow ( $\dot{Q}$ di), arteriovenous oxygen difference $\left[(\mathrm{A}-\mathrm{V}) \mathrm{O}_{2}\right.$ di], and oxygen consumption $\left(\dot{\mathrm{V}}_{2} \mathrm{di}\right)$ as functions of minute ventilation $\left(\dot{\mathrm{V}}_{\mathrm{E}}\right)$ in 16 healthy dogs which inhaled $5 \% \mathrm{CO}_{2}$ or $5 \% \mathrm{CO}_{2}$ and $14 \%$ $\mathrm{O}_{2}$. The line for each dog connects the points measured during quiet breathing and hyperventilation. 
TABLE III

Minule Ventilation, Diaphragmatic Oxygen Consumption and the Diaphragmatic Oxygen Cost of Breathing during Quiet Breathing $(Q B)$ and Hyperventilation $(H V)$

\begin{tabular}{|c|c|c|c|c|c|c|}
\hline & \multicolumn{2}{|c|}{$\dot{\mathbf{V}}_{\mathbf{E}}$} & \multicolumn{2}{|c|}{$\dot{\mathrm{V}} \mathrm{O}_{2} \mathrm{di}$} & \multirow{2}{*}{$\frac{\dot{\mathrm{V}} \mathrm{O}_{2} \mathrm{di} / \mathrm{VE}_{\mathrm{E}}}{\mathrm{QB}}$} & \multirow{2}{*}{$\frac{\Delta \dot{\mathrm{V}}_{2} \mathrm{di} / \Delta \dot{\mathrm{V}}_{\mathrm{F}}}{\mathrm{HV}-\mathrm{QB}}$} \\
\hline & QB & HV & QB & HV & & \\
\hline & \multirow{2}{*}{\multicolumn{2}{|c|}{$\begin{array}{l}\text { liters BTPS/min } \\
\text { ogs }\end{array}$}} & \multicolumn{2}{|c|}{$m l / m i n$} & $m l / l i t e r$ & $m l / l i t e r$ \\
\hline \multicolumn{5}{|c|}{ Healthy dogs } & & \\
\hline 29 & 6.57 & 19.80 & 1.5 & 2.7 & 0.23 & 0.09 \\
\hline 30 & 6.08 & 11.11 & 1.3 & 2.3 & 0.21 & 0.20 \\
\hline 31 & 6.48 & 17.21 & 1.5 & 1.8 & 0.23 & 0.03 \\
\hline 32 & 4.82 & 21.98 & 2.0 & 3.9 & 0.41 & 0.11 \\
\hline 33 & 7.04 & 40.26 & 1.6 & 4.5 & 0.23 & 0.09 \\
\hline 34 & 6.63 & 26.97 & 1.3 & 2.0 & 0.20 & 0.03 \\
\hline 38 & 5.02 & 16.33 & 1.5 & 2.4 & 0.30 & 0.08 \\
\hline 56 & 8.82 & 42.34 & 1.1 & 2.5 & 0.12 & 0.04 \\
\hline 57 & 3.03 & 11.25 & 1.0 & 2.0 & 0.33 & 0.02 \\
\hline 58 & 4.03 & 12.73 & 1.6 & 3.6 & 0.40 & 0.23 \\
\hline 59 & 4.58 & 11.41 & 1.5 & 3.6 & 0.33 & 0.31 \\
\hline 60 & 4.39 & 13.98 & 2.0 & 3.3 & 0.46 & 0.14 \\
\hline 61 & 5.96 & 15.36 & 1.2 & 2.5 & 0.20 & 0.14 \\
\hline 62 & 7.75 & 19.23 & 1.9 & 4.6 & 0.25 & 0.24 \\
\hline 86 & 6.21 & 19.35 & 1.9 & 4.6 & 0.31 & 0.21 \\
\hline 90 & 4.00 & 27.49 & 0.7 & 2.6 & 0.17 & 0.19 \\
\hline Mean & & & & & 0.27 & 0.13 \\
\hline$\underset{t^{*}}{\mathrm{SD}}$ & & & & & 0.09 & $4.61^{0.09}$ \\
\hline$P^{*}$ & & & & & & 0.001 \\
\hline \multicolumn{7}{|c|}{ Dogs with pneumonia } \\
\hline 21 & 10.28 & & 3.4 & & 0.33 & \\
\hline 46 & 8.53 & & 3.3 & & 0.39 & \\
\hline 48 & 21.80 & & 6.7 & & 0.31 & \\
\hline 55 & 10.56 & & 4.4 & & 0.42 & \\
\hline Mean & & & & & 0.36 & \\
\hline SD & & & & & 0.05 & \\
\hline$t \ddagger$ & & & & & 1.81 & \\
\hline$P \ddagger$ & & & & & $<0.1$ & \\
\hline
\end{tabular}

* Difference between $\dot{\mathrm{V}} \mathrm{o}_{2} \mathrm{di} / \dot{\mathrm{V}}_{\mathrm{E}}$ and $\Delta \dot{\mathrm{V}} \mathrm{o}_{2} \mathrm{di} / \Delta \dot{\mathrm{V}}_{\mathrm{E}}$ in healthy dogs. $\ddagger$ Difference between $\dot{\mathrm{V}} \mathrm{o}_{2} \mathrm{di} / \dot{\mathrm{V}}_{\mathrm{E}}$ in healthy dogs as compared to dogs with pneumonia.

cantly to $2.3 \pm \mathrm{SD} 0.8 \mathrm{ml}$ of $\mathrm{O}_{2} / \mathrm{min}$ per $100 \mathrm{~g}$ during hyperventilation $(P<0.001)$.

The relationship between minute ventilation and diaphragmatic oxygen consumption can be examined in greater detail by comparing the ratio of the total diaphragmatic oxygen consumption, expressed in milliliters per minute, to the ventilation measured in liters BTPS per minte. In 16 normal animals, the ratio of diaphragmatic oxygen consumption to minute ventilation was $0.27 \pm 0.09 \mathrm{ml} /$ liter during quiet breathing (Table III). Under comparable circumstances, the value of the ratio in the four animals with pneumonia was $0.36 \pm$ SD 0.05 $\mathrm{ml} /$ liter (Table III). Although this level of oxygen cost was slightly higher than in the healthy dogs, the difference was not significant $(P<0.1)$.

When minute ventilation and diaphragmatic oxygen consumption were increased by means of $5 \% \mathrm{CO}_{2}$ or $5 \%$
$\mathrm{CO}_{2}$ and $14 \% \mathrm{O}_{2}$ inhalation, the ratio of the increment in diaphragmatic oxygen consumption to the increment in minute ventilation averaged $0.13 \pm \mathrm{SD} \quad 0.09 \mathrm{ml} / \mathrm{liter}$. This value was significantly lower than the ratio of diaphragmatic oxygen consumption to ventilation measured during quiet breathing in the same animals $(P<$ 0.001 ).

\section{DISCUSSION}

Validity of the method. The left inferior phrenic vein with its tributaries is the only major venous drainage system for the left hemidiaphragm in the dog. It does not anastomose significantly with other regional venous systems, including those draining the chest wall and the adrenal venous system. Blood can be sampled at $5-10 \mathrm{ml} / \mathrm{min}$ from the left inferior phrenic vein without contamination from the inferior vena cava.

Perfusion per unit mass of diaphragm was found to be quite uniform except at the periphery of the venous drainage area. The bulk of the flat muscle sheet has comparable radioactivity $3 \mathrm{~min}$ after cessation of a saturating ${ }^{133} \mathrm{Xe}$ infusion, whereas there is more radioactivity in areas immediately adjacent to the chest wall and central tendon, and in the crural fibers. Since these latter areas represent the end of an essentially nonanastomotic vascular network, it is probable they receive less blood flow.

It was not possible to sample blood from individual venous tributaries. Nevertheless, the uniform distribution of radioactivity in the center of the diaphragmatic muscle suggests that blood flow to this area is uniform, and that use of the Kety-Schmidt method to measure diaphragmatic muscle blood flow is valid.

The average level of blood flow to the diaphragm, measured during quiet breathing, was 22 $2 \mathrm{SD} 6 \mathrm{ml} / \mathrm{min}$ per $100 \mathrm{~g}$. This approximately half the level of diaphragmatic perfusion previously measured in this laboratory from the clearance of ${ }^{133} \mathrm{Xe}$ after intramuscular injection (4). The difference in estimates might result from several factors. It is possible that the earlier estimate was too high, since analysis of the initial clearance rate of xenon by the method of Lassen, Lindbjerg, and Munck $(21,26)$ yielded, on the average, a $20 \%$ lower blood flow value (4). It is also possible that the present estimate of blood flow is too low. No correction was made for the transit delay through the sampling catheter. At most this is $\frac{1}{4} \mathrm{~min}$, which would cause a $15 \%$ underestimate of blood flow.

Another problem stemming from use of the KetySchmidt method to measure diaphragmatic perfusion is related to the equilibrium tracer concentration. The error involved is more difficult to evaluate. In these studies, equilibrium venous blood krypton concentration after $20-30 \mathrm{~min}$ of infusion was $20 \pm$ SD $12 \%$ lower than 
the simultaneous arterial blood tracer level. Prolonging the infusion period to $40 \mathrm{~min}$ made little difference. In general, the difference between arterial and venous blood tracer levels at the end of the infusion period was greater when the diaphragm contracted gently, and less when the diaphragm contracted vigorously.

The reason for the persistant arteriovenous krypton difference after prolonged infusion is not apparent. No significant loss from the venous sampling catheter was detected. It is possible that there was a loss of tracer from the diaphragm to adjacent tissue, particularly into the lung, since Gregg, Longino, Green, and Czerwonka found large losses of nitrous oxide from the exposed surface of the heart in an open-chest animal preparation (27). Other investigators have noted a 5-10\% difference between arterial and coronary sinus blood indicator levels when either krypton or nitrous oxide was used to measure myocardial blood flow by the Kety-Schmidt method $(15,28-31)$. Several workers attributed the differences to inhomogeneity of blood flow within the myocardium, or to loss into epicardial fat (29-31).

It was not possible to estimate the rate of loss of krypton from the perfused living diaphragm. Xenon diffuses very slowly from excised diaphragmatic strips, but the conditions are not comparable to those in perfused muscle. It must be pointed out that if there were a steady-state loss of tracer from tissue during a constant rate saturating infusion, then both tissue and venous blood tracer concentrations should be lower than arterial blood tracer levels. Further, muscle tissue and muscle venous blood tracer levels decay at virtually the same rate after cessation of a prolonged infusion of either hydrogen or xenon $(19,20)$. Therefore, use of the venous tracer level as representative of equilibrium tissue level seems justified.

To summarize, blood flow to the diaphragm may have been overestimated by $20 \%$ when calculated from xenon clearance, and underestimated by $15 \%$ when calculated from the equilibrium level and integrated diaphragmatic arteriovenous difference of krypton. The combined effect of these correction factors is to yield quite similar estimates of blood flow to the diaphragm from both methods. During quiet breathing, diaphragmatic perfusion in the dog probably lies around $25 \mathrm{ml} / \mathrm{min}$ per $100 \mathrm{~g}$, which is very close to the level of $31 \mathrm{ml} / \mathrm{min}$ per $100 \mathrm{~g}$ measured in the unanesthetized rhesus monkey by the radioactive microsphere method. ${ }^{1}$

The reproducibility of the present methods of measuring diaphragmatic blood flow and oxygen consumption can be compared with estimates of myocardial blood flow and oxygen consumption made by the Kety-Schmidt technique. When the present reproducibility data were

\footnotetext{
${ }^{1}$ Forsyth, R. P. Personal communication.
}

recalculated according to the formula of Jorgensen, Kitamura, Gobel, Taylor, and Wang (29), the reproducibility of the diaphragmatic blood flow measurement was somewhat poorer, and the reproducibility of diaphragmatic oxygen consumption was somewhat better than the values reported by Jorgensen and his colleagues for the myocardium.

The present method of measuring diaphragmatic blood flow offers several advantages over the xenon clearance method. The need for laparotomy to expose the diaphragm is eliminated, and there is no injection trauma to the diaphrgam. Sampling diaphragmatic venous blood permits measurement of the diaphragmatic arteriovenous difference in blood oxygen content, and therefore, calculation of diaphragmatic oxygen consumption. Far fewer experiments were lost than with the xenon method. Finally, the scatter of data between animals was much lower. The standard deviation of diaphragmatic blood flow measured during quiet breathing was $27 \%$ of the mean value in the present study, whereas with the xenon clearance method it was $52 \%$ of the mean.

Physiological considerations. When the diaphragm contracts gently to sustain quiet breathing in normotensive dogs, the primary determinant of its perfusion is the level of cardiac output (Fig. 4). These observations confirm previous results obtained by the xenon clearance method (4). The effect of hypotension on diaphragmatic blood flow was not studied.

The oxygen utilization of the diaphragm is rather constant during quiet breathing (Table I). As with diaphragmatic blood flow, there is no correlation in the control period between diaphragmatic oxygen consumption and minute ventilation (Fig. 5). The relative constancy of diaphragmatic oxygen consumption is independent of changes in blood flow. Whenever diaphragmatic blood flow is unusually high or low for quiet breathing, there is a reciprocal change in oxygen extraction. Hence a plot of diaphragmatic blood flow and arteriovenous oxygen difference fits a rectangular hyperbola that is an isopleth of diaphragmatic oxygen utilization (Fig. 6). The value of this isopleth, $1.14 \mathrm{ml} / \mathrm{min}$ per $100 \mathrm{~g}$, is very close to the measured average value of $1.2 \mathrm{ml} / \mathrm{min}$ per $100 \mathrm{~g}$ under control conditions. These data suggest a relative absence of autoregulation of diaphragmatic blood flow during minimal efforts.

Hyperventilation consistently and significantly increases diaphragmatic blood flow, arteriovenous oxygen difference, and oxygen consumption, but the changes are not large (Fig. 7). If the average changes are expressed as a percent of control values, then a $100 \%$ increase in minute ventilation is associated with only a $13 \%$ increase in blood flow to the diaphragm, and a $19 \%$ increase in the diaphragmatic arteriovenous oxygen content difference. To support this increase in ventila- 
tion, diaphragmatic oxygen utilization is augmented by $40 \%$.

Oxygen utilization by respiratory muscles is customarily related to the level of ventilation by determining the amount of oxygen required to provide a liter of ventilation. In the method of Liljestrand, oxygen cost is calculated as the quotient of the increment in whole body oxygen consumption caused by hyperventilation, and the increment in minute ventilation (5). In like fashion, the diaphragmatic oxygen cost of breathing was computed from the increments in diaphragmatic oxygen consumption and minute ventilation. The average value in anesthetized animals that increased their ventilation some $240 \%$ over controls levels was $0.13 \pm \mathrm{SD} 0.09 \mathrm{ml}$ $\mathrm{O}_{2} /$ liter of ventilation (Table III).

From the formula of Albers, which relates total body oxygen consumption to minute ventilation in the dog (12), it can be estimated that $2.5 \mathrm{ml}$ of oxygen are required to support a ventilation of $5 \mathrm{liter} / \mathrm{min}$. Hence the oxygen cost of breathing is $0.5 \mathrm{ml} /$ liter. This is approximately four times larger than the current estimate of the diaphragmatic oxygen cost of breathing. It has been suggested that the apparatus used by Albers had a high internal resistance to air flow (13). Another reason for the discrepancy may lie in the marked differences in experimental techniques.

The most important factor in evaluating the relationship between minute ventilation and diaphragmatic oxygen consumption is the extent to which any level of ventilation is supported by inspiratory muscles other than the diaphragm. It is generally accepted that the diaphragm is the major or sole muscle employed during quiet breathing (32). Fluoroscopic observation revealed relatively uniform diaphragmatic excursion when dogs breathed quietly, but this could not quantified. There were no obvious differences in the way the diaphragms moved in the animals with pneumonia.

It was not possible to assess recruitment of other inspiratory muscles in this study. In the rabbit extradiaphragmatic muscles contribute an average of $25 \%$ of the tidal volume when tidal volume is maximal during rebreathing. However, there is considerable variation in individual animals (32). Such variation would help to explain the large scatter in the estimates of the diaphragmatic oxygen cost of breathing.

Another cause of scatter in these estimates may be differences in airway resistance. Some animals without overt pneumonia had much more bronchial secretion than others.

Despite the variation, it is readily apparent that the increase in diaphragmatic energy expenditure required for modest levels of hyperventilation is small. For example, the diaphragm of a typical $20-\mathrm{kg}$ dog weighs 110 g. Dúring quiet breathing at 5 liters $/ \mathrm{min}$, the diaphragm would consume about $1.3 \mathrm{ml}$ of oxygen $/ \mathrm{min}$. Of this, about $0.8 \mathrm{ml}$ of $\mathrm{O}_{2} / \mathrm{min}$ is needed for basal metabolism, and $0.5 \mathrm{ml}$ of $\mathrm{O}_{2} / \mathrm{min}$ is required to support ventilation. The oxygen cost to the diaphragm of quiet breathing is, therefore, $0.5 / 5$ or $0.10 \mathrm{ml} /$ liter. When the animal breathes at $20 \mathrm{liter} / \mathrm{min}$, the increased ventilation is accomplished at an oxygen cost to the diaphragm of $0.13 \mathrm{ml} /$ liter. Hence the increase in diaphragmatic oxygen consumption would be $15 \times 0.13$ or about $2 \mathrm{ml} / \mathrm{min}$.

The chance occurrence of multilobar pneumonia in four dogs provided some insight on the effect of a restrictive pulmonary disease on the energetics of the diaphragm. At the same level of anesthesia as used for normal animals, the sick dogs hyperventilated (Table I). Their diaphragmatic blood flow and oxygen consumption were also above normal (Table I), and tended to be proportional to the increased ventilation (Fig. 4). The oxygen cost of increasing ventilation was not measured in these animals, but the ratio of diaphragmatic oxygen consumption to minute ventilation during the control period was not significantly different from the ratio found in healthy animals (Table III).

This unexpected result makes it appear that it is almost as easy to ventilate stiff lungs as it is to ventilate normal lungs. The following example indicates otherwise. A typical sick dog weighing $20 \mathrm{~kg}$ breathes 10 liter/ min, and its diaphragm consumes $3.3 \mathrm{ml}$ of oxygen/ min. If the basal metabolism of the diaphragm is normal, then about $2.5 \mathrm{ml}$ of oxygen are expended to support the minute ventilation. Thus, the diaphragmatic oxygen cost of breathing is $2.5 / 10$ or $0.25 \mathrm{ml} /$ liter. Pneumonia increases diaphragmatic oxygen consumption through two mechanisms. First is the increase in minute ventilation per se, and second is the two- to threefold increase in the energy required for each liter of ventilation.

\section{ACKNOWLEDGMENTS}

This study was supported by a grant from the New York Heart Association and by grants HE-02001, HE-05741, and HE-05443 from the National Institutes of Health.

\section{REFERENCES}

1. Anrep, G. V., S. Cerqua, and A. Samaan. 1933-34. The effect of muscular contraction upon the blood flow in the skeletal muscle, in the diaphragm, and in the small intestine. Proc. R. Soc. Lond. B. Biol. Sci. 114: 245.

2. Mott, J. C. 1953. The circulation of the thoracic cage in the dog and its reaction to haemorrhage. J. Physiol. (Lond.). 121: 80 .

3. Forsyth, R. P., B. I. Hoffbrand, and K. L. Melmon. 1970. Redistribution of cardiac output during hemorrhage in the unanesthetized monkey. Circ. Res. 27: 311.

4. Rochester, D. F., and M. Pradel-Guena. 1973. Measurement of diaphragmatic blood flow in dogs from xenon ${ }^{133}$ clearance. J. Appl. Physiol. 34: 68. 
5. Liljestrand, G. 1918. Untersuchungen über Atmungsarbeit. Skand. Arch. Physiol. 35: 199.

6. Cournand, A., and D. W. Richards, Jr. 1954. The oxygen cost of breathing. Trans. Assoc. Am. Physicians Phila. 67: 162 .

7. McKerrow, C. B., and A. B. Otis. 1956. Oxygen cost of hyperventilation. J. Appl. Physiol. 9: 375.

8. Campbell, E. J. M., E. K. Westlake, and R. M. Cherniack. 1957. Simple methods of estimating oxygen consumption and efficiency of the muscles of breathing. J. Appl. Physiol. 11: 303.

9. Bartlett, R. G., Jr., H. F. Brubach, and H. Specht. 1958. Oxygen cost of breathing. J. Appl. Physiol. 12: 413.

10. Cherniack, R. M. 1959. The oxygen consumption and efficiency of the respiratory muscles in health and emphysema. J. Clin. Invest. 38: 494.

11. Fritts, H. W., Jr., J. Filler, A. P. Fishman, and A. Cournand. 1959. The efficiency of ventilation during voluntary hyperpnea: studies in normal subjects and in dyspneic patients with either chronic pulmonary emphysema or obestiy. J. Clin. Invest. 38: 1339.

12. Albers, C. 1961. Der Mechanismus des Wärmehechelns beim Hund. II. Der respiratorische Stoffwechsel wärhrend des Wärmehechelns. (The mechanism of thermal stress in the dog. II. Metabolism during thermal stress.) Pfiugers Arch. ges. Physiol. 274: 148.

13. Spaich, P., W. Usinger, and C. Albers. 1968. Oxygen cost of panting in anesthetized dogs. Respir. Physiol. 5: 302 .

14. Rochester, D. F. 1970. Measurement of diaphragmatic blood flow and oxygen consumption in the dog. J. Clin. Invest. 49: 80a.

15. Kety, S. S., and C. F. Schmidt. 1945. The determination of cerebral blood flow in man by the use of nitrous oxide in low concentrations. Am. J. Physiol. 143: 53.

16. Kety, S. S., and C. F. Schmidt. 1948. The nitrous oxide method for the quantitative determination of cerebral blood flow in man: theory, procedure, and normal values. J. Clin. Invest. 27: 476.

17. Hansen, A. T., B. F. Haxholdt, E. Husfeldt, N. A Lassen, O. Munck, H. R. Sorensen, and $K$. Winkler. 1956. Measurement of coronary blood flow and cardiac efficiency in hypothermia by use of radioactive krypton-85. Scand. J. Clin. Lab. Invest. 8: 182.

18. Hardewig, A., D. F. Rochester, and W. A. Briscoe. 1960. Measurement of solubility coefficient of krypton in water, plasma and human blood, using radioactive $\mathrm{Kr}^{85}$. J. Appl. Physiol. $15: 723$.

19. Sejrsen, P., and K. H. Tønnesen. 1968. Inert gas diffusion method for measurement of blood flow using saturation techniques. Comparison with directly mea- sured blood flow in the isolated gastrocnemius muscle of the cat. Circ. Res. 22: 679.

20. Aukland, K., B. F. Bower, and R. W. Berliner. 1964. Measurement of local blood flow with hydrogen gas. Circ. Res. 14 : 164.

21. Lassen, N. A., I. F. Lindbjerg, and O. Munck. 1964. Measurement of blood-flow through skeletal muscle by intramuscular injection of xenon-133. Lancet. 1: 686.

22. Holzman, G. B., H. N. Wagner, Jr., M. Iio, D. Rabinowitz, and K. L. Zierler. 1964. Measurement of muscle blood flow in the human forearm with radioactive krypton and xenon. Circulation. 30: 27.

23. Yeh, S-Y., and R. E. Petersen. 1965. Solubility of krypton and xenon in blood, protein solutions, and tissue homogenates. J. Appl. Physiol. 20: 1041.

24. Van Slyke, D. D., and J. M. Neill. 1924. The determination of gases in blood and other solutions by vacuum extraction and manometric measurement. I. J. Biol. Chem. $61: 523$.

25. Caldwell, P. R. B., U. Echeverri, M. M. Kilcoyne, and H. W. Fritts, Jr. 1970. Observations on a model of proliferative lung disease. II. Description of pulmonary gas exchange and comparison of Fick and dye cardiac outputs. J. Clin. Invest. 49: 1311.

26. Lassen, N. A. 1964. Muscle blood flow in normal man and in patients with intermittant claudication evaluated by simultaneous $\mathrm{Xe}^{183}$ and $\mathrm{Na}^{24}$ clearances. J. Clin. Invest. $73: 1805$.

27. Gregg, D. E., F. H. Longino, P. A. Green, and L. J. Czerwonka. 1951. A comparison of coronary flow determined by the nitrous oxide method and by a direct method using the rotameter. Circulation. 3: 89.

28. Hedworth-Whitty, R. B., E. Housley, and A. S. Abraham. 1969. An improved technique for measuring changes in myocardial perfusion by the nitrous oxide method. Cardiovasc. Res. 3 : 496.

29. Jorgensen, C. R., K. Kitamura, F. L. Gobel, H. L. Taylor, and Y. Wang. 1971. Long-term precision of the $\mathrm{N}_{2} \mathrm{O}$ method for coronary flow during heavy upright exercise. J. Appl. Physiol. 30: 338.

30. Klocke, F. J., D. R. Rosing, and D. E. Pittman. 1969. Inert gas measurements of coronary blood flow. $\mathrm{Am}$. J. Cardiol. 23 : 548.

31. Eckenhoff, J. E., J. H. Hafkenschiel, M. H. Harmel, W. T. Goodale, M. Lubin, R. J. Bing, and S. S. Kety. 1948. Measurement of coronary blood flow by the nitrous oxide method. Am. J. Physiol. 152: 356.

32. Mognoni, P., F. Saibene, and G. Sant 'Ambrogio. 1969. Contribution of the diaphragm and other inspiratory muscles to different levels of tidal volumes and static inspiratory effort in the rabbit. J. Physiol. 202: 517. 